\title{
The art of acting students' feelings and emotions
}

\begin{abstract}
Emotion involves a wide variety of feelings, thoughts, and behavior. The experiences that caused emotion are subjective experiences, or experienced from an individual point of view. Emotion for the undergraduate students is often associated with mood, temperament, personality, and disposition. Therefore, this study concentrated on an art of acting course, a compulsory course for students who undertake the minor in performing arts. The course was also opened to all students at the university. This course was to enhance students to be confident, vocal and most importantly to overcome their fear of performing. The objectives of the study were to find out the content of discussion of subjects by using the content analysis and to identify the types of emotion while carrying out their task. The subjects consisted of 10 undergraduate students from a class of the art of acting. The subjects were to write their own script, prepare the props, setting and most importantly act in the play. All the subjects have roles in the play. The subjects' discussions and conversations were taped for three hours a week until the fourteenth week. The conversations were analyzed and the subjects' feelings and emotion will be identified.
\end{abstract}

Keyword: art of acting, emotions, content analysis 